\title{
Considerações teórico-metodológicas sobre o pro- cesso analítico na dissertação Suite da Epopéia Bra- sileira: análise da obra composicional de Delsuamy Vivekananda Medeiros (1938-2004)
}

Theoretical and methodological considerations about the analytical process in the Suite da Epopéia Brasileira: análise da obra compo-

sicional de Delsuamy Vivekananda Medeiros (1938-2004)

RESUMO

por Daniel Ribeiro Medeiros

Este artigo apresentará considerações sobre o corpus teórico-metodológico que deu sustentação ao processo de análise estilística da obra composicional de Delsuamy Vivekananda Medeiros. Primeiramente, será apresentada uma introdução, versando sobre um panorama geral da dissertação, colocando o leitor a par da temática, dos problemas encontrados para a realização da pesquisa, bem como de seus resultados. Após, serão discutidos aspectos teórico-metodológicos, discorrendo sobre referenciais teóricos e conceitos significativos, bem como as estratégias metodológicas adotadas para a realização das análises. Dessa forma, pretende-se contribuir com o amplo processo de reflexão relacionado à Análise Musical no Brasil.

Palavras-chave: Suite da Epopéia Brasileira; Análise Musical; Musicologia; Violão; Metodologia.

\section{ABSTRACT}

This article will present considerations about theoretical and methodological aspects that gave support to the analytical process involved in the Delsuamy Vivekananda Medeiros's compositional work. Firstly, will be presented a general outlook of the dissertation, making the reader knows about: the thematic, the problems involved in the realization of the research, as well as the conclusions. Secondly, will be discussed the theoretical, methodological and conceptual aspects taken from the reference authors selected. These authors provided a theoretical field for the analysis. In this way, the main aim of this article is to contribute with reflections related with Musical Analysis field in Brasil.

Keywords: Suite da Epopéia Brasileira; Musical Analysis; Musicology; Clasical Guitar; Methodology. 
Considerações teórico-metodológicas sobre o processo analítico na dissertação Suite da Epopéia Brasileira: análise da obra composicional de Delsuamy Vivekananda Medei$\operatorname{ros}(1938-2004)$

\section{Introdução}

A dissertação Suite da Epopéia Brasileira: análise da obra composicional de Delsuamy Vivekananda Medeiros (1938-2004) aborda a obra composicional do violonista-compositor Delsuamy Vivekananda Medeiros (1938-2004)'. Após levantamento de parte de sua obra ${ }^{2}$ (manuscritos), foi realizado um estudo analítico que teve como principais questões:

- Qual o perfil estilístico da obra para violão solo de Delsuamy Vivekananda Medeiros no escopo composicional violonístico brasileiro no século XX?

- Quais elementos apresentam traços estilísticos caracterizadores?

Dessa forma, a investigação foi dirigida à análise estilística (MEYER, 1989). Também foram utilizados outros referenciais neste estudo, os quais serão apresentados nos tópicos subsequentes.

Por outro lado, cabe ressaltar, outra atividade que foi necessária à realização do trabalho. Em decorrência da escassez de literatura que tratasse de sua trajetória musical (composição, performance, docência, dentre outras atividades), foi necessário o levantamento de documentos que pudessem oferecer maiores informações. Sendo assim, foi necessário considerar uma série de fatores externos ao próprio processo analítico.

Foram encontradas breves menções sobre Vivekananda nos livros História Iconográfica do Conservatório de Música da UFPel (2005) e História do Conservatório de Música de Pelotas (1992), bem como em artigos encontrados nas revistas Violão e Mestres (1968) e Assovio (2001), o que justificou a importância do levantamento de fontes primárias, tais como matérias de jornais, programas de concertos, curriculum vitae, cartas, gravações, entre outras, a fim de se registrar parte da trajetória profissional deste músico³. A maior parte do material foi coletada no arquivo pessoal do violonista 4 . Na Bibliotheca Pública Pelotense, foram levantadas várias matérias (críticas, anúncios de concertos e de aulas, bem como outros artigos) em edições do Jornal Diário Popular (Pelotas). Em críticas de seus concertos foram encontradas tanto comentários sobre peças ainda não encontradas como apreciações estéticas das mesmas, demonstrando a circulação de sua obra frente ao público da época e de como a crítica às recebia.

A dissertação foi dividida em dois grandes capítulos. No capítulo I, foram abordados

$1 \quad$ Para informações sobre o músico, indica-se a leitura dos seguintes artigos: Delsuamy Vivekananda Medeiros (1938 - 2004): Trajetória de um violão no Rio Grande do Sul (2009), disponível em: 〈http://www.embap.pr.gov.br/arquivos/File/simposio/viola02009/12.pdf〉; Delsuamy Vivekananda Medeiros (1938-2004): relações entre performer e contexto (2012), disponível em 〈http://www.ceart.udesc.br/ dapesquisa/musica/index.htmlı; além da referida dissertação.

2 No catálogo do músico, levantado em seu acervo particular, constam mais obras, as quais não foram encontradas até o momento.

3 Tais fontes também contribuíram com o próprio processo de análise estilística.

$4 \quad 0$ qual encontra-se em posse de sua família. Agradeço desde já os familiares pela disponibilidade e compreensão da importância deste trabalho. 
Considerações teórico-metodológicas sobre o processo analítico na dissertação Suite da Epopéia Brasileira: análise da obra composicional de Delsuamy Vivekananda Medeiros (1938-2004)

aspectos sobre a carreira musical de Vivekananda (docência, performance, composição e outras atividades). Além disso, também foram abordados:

- Análise do repertório costumeiramente executado pelo violonista, o qual foi colhido tanto em programas de concertos, como no repertório contido em seu acervo particular de partituras;

- Desenvolvimento de um catálogo das composições encontradas e não-encontradas, com informações sobre o estado físico deste material, sua circulação (concertos), etc.

0 capítulo II (Análises) está dividido em quatro partes e apresenta o diálogo de sua obra com as de outros autores. Em Características extra-musicais, são abordados os títulos alusivos (elementos programáticos); em Recursos idiomáticos, os elementos técnico/ violonísticos que refletem aspectos idiomático-instrumentais na obra do violonista/ compositor gaúcho. As Análises de superfície apresentam amostras a respeito dos aspectos estruturais, tais como organização formal, estruturação, processos motívicos, bem como o modalismo. Nas Análises estruturais são tratados aspectos da articulação das estruturas musicais em níveis mais aprofundados e lineares (análise schenkeriana).

Como resultado final, a dissertação apresentou as seguintes considerações. Em primeiro lugar, tornou possível o registro e conhecimento sobre um músico que até então sequer circulava como temática em investigações musicais. Além disso, mostrou que existe considerável material sobre Vivekananda, principalmente quando consideradas as matérias de jornais. Por último, o catálogo de composições se tornou fundamental, uma vez que sistematiza sua obra, tanto através de peças encontradas como as não-encontradas, disponibilizando informações importantes para futuras investigações. No que diz respeito ao foco analítico, dialogar sua obra com a produção composicional brasileira para violão, mostrou um grande desafio investigativo em decorrência do vasto contexto surgido. Isso ocorreu, a nosso ver, principalmente pelas bases estéticas e pedagógicas sobre as quais o violão de "concerto" no Brasil esteve ligado ("Escola de Tárrega"). Observando obras de violonistas como João Pernambuco (1883-1947), Dilermando Reis (1916-1977), além de outros, notam-se modos de estruturação, articulação, ornamentação, etc, muitas vezes semelhantes com aqueles observados nas obras de Francisco Tárrega. Isso nos coloca diante de uma via pela qual a música para violão no Brasil passou. Portanto, dentro deste contexto, observa-se um aspecto cultural importante que foi considerado na dissertação.

Mais especificamente, as análises mostraram que sua obra dialoga com o conceito de obras programáticas, alinhando-se a uma característica bastante ligada à produção musical romântica (século XIX). Também na mesma linha, variados recursos idiomáticos encontrados em obras de Tárrega, Barrios, Saleiro, dentre outros, encontram na estética clássico-romântica um referencial. Por outro lado, suas composições também dialogam com características significativas da obra violonística de Heitor Villa-Lobos. As análises de superfície (forma, processo motívico e modalidade) mostram que os processos de organização musical apresentam características comuns às obras de outros 
Considerações teórico-metodológicas sobre o processo analítico na dissertação Suite da Epopéia Brasileira: análise da obra composicional de Delsuamy Vivekananda Medeiros (1938-2004)

autores violonistas. Outra característica fica por conta da manipulação de sonoridades modais, muito características na produção composicional brasileira. As análises estruturais apontam para uma obra que não articula estruturas musicais como sentenças, períodos, dentre outras, bem como um amplo processo de modulações, estabelecendo cenários tonais variados. Isso demonstra que sua obra tem como principal ocorrência a manifestação de variados processo de movimentos em torno de uma nota estrutural, bem como notas retidas (retained notes).

\section{Fundamentação teórica}

Para fundamentar teoricamente o trabalho, foram levantados referenciais relacionados à análise musical, constituindo, dessa forma, o background do trabalho. Em linhas gerais, o processo de análise estilística regeu metodologicamente a investigação, uma vez que os pressupostos teóricos de Meyer (1989) também dão conta deste aspecto. A análise de superfície, apoiada basicamente em Schoenberg (1991), bem como a abordagem schenkeriana através da perspectiva de Salzer (1952), nas análises estruturais, foram essenciais para o aprofundamento da compreensão da obra analisada.

\section{Análise estilística}

Foram utilizados como base teórica principal os conceitos e procedimentos de Leonard B. Meyer, em Style and Music - theory, history and ideology (1989). Para situarmos o assunto, torna-se necessário expor alguns dos fundamentos que o autor traz.

0 conceito de estilo

Conforme Meyer (1989), o estilo se caracteriza como a "replicação de uma padronização, tanto no comportamento humano como pelos artefatos produzidos pelo comportamento humano, que resultam de uma série de escolhas feitas dentro de algum conjunto de restrições" (MEYER, 1989, p.3). No âmbito musical, este conceito dá conta de uma variada gama de recursos musicais culturalmente disponíveis ao compositor: linguagens modal, tonal, atonal; gêneros como rock, blues, choro, samba, etc; modos de estruturação de materiais característicos de variados estilos, etc.

Meyer (1989) observa a relação do sujeito (compositor) com o contexto cultural (materiais, recursos disponíveis) como diálogo fundamental na construção de um estilo. Conforme o autor, "um estilo pessoal de falar ou escrever, por exemplo, resulta em grande parte de escolhas lexicais, gramaticais e sintáticas feitas dentro de restrições da linguagem e do dialeto que o homem aprendeu a usar, mas que não criou por si próprio" (MEYER, 1989, p.3). Dessa forma, as escolhas dialogam com as circunstâncias histórico/culturais nas quais os indivíduos ou grupos estão inseridos. Sendo assim, um 
Considerações teórico-metodológicas sobre o processo analítico na dissertação Suite da Epopéia Brasileira: análise da obra composicional de Delsuamy Vivekananda Medeiros (1938-2004)

compositor, mesmo dentro de uma determinada cultura musical e estando em uma relação consensual ou não com tais premissas estéticas, apresenta uma abordagem própria dentro de um determinado sistema musical ou linguagem, conferindo traços estilísticos próprios.

Pascall (2001), por sua vez, apresenta a seguinte definição de estilo:

Um termo que denota maneira de discurso, modo de expressão; mais particularmente, a maneira na qual uma obra de arte é executada. Na discussão da música, a qual é orientada em direção a relacionamentos em vez de significados, o termo levanta dificuldades especiais; pode ser usado para denotar a música característica de um compositor individual, de um período, de uma área ou centro geográfico, ou de uma sociedade ou função social (PASCALL, 2001, p.638).

Do ponto de vista do enfoque, o autor ainda exemplifica:

Um estilo pode ser visto como uma síntese de outros estilos; casos óbvios são os estilos para teclado de J. S. Bach e o estilo operístico de Mozart (ambos compreendem distintos estilos texturais, distintos estilos harmônicos, distintos estilos melódicos, etc., e ambos são fusões de várias tradições estilísticas). Um estilo também representa um âmbito ou séries de possibilidades definidas por um grupo de exemplos particulares, tais como noções de 'estilo homofônico' e 'estilo cromático' (PASCALL, 2001, p.638).

Além disso, o estilo [...] manifesta-se em usos característicos da forma, textura, harmonia, melodia, ritmo e ethos; e é apresentado por personalidades criativas, condicionadas por fatores históricos, sociais e geográficos, recursos de execução e convenções (PASCALL, 2001, p.638).

Assim como Meyer (1989), Pascall (2001) também observa a importância do meio cultural ao qual determinado compositor, músico, ou mesmo público, ouvintes, estão inseridos. A compreensão estilística, sendo assim, depende do reconhecimento de elementos e formas de organização capazes de dar sentido e, principalmente, esclarecer acerca da identidade de determinado estilo ou gênero. Beard e Gloag (2005) apresentam a seguinte discussão:

0 conceito de estilo se refere à maneira ou modo de expressão, o meio o qual os gestos musicais são articulados. Neste sentido, pode ser relacionado ao conceito de identidade. Na música, o estilo requer a consideração de recursos técnicos, tais como melodia, textura, ritmo e harmonia, e diz respeito aos modos os quais estes recursos operam, independentemente ou em conjunção, ou como categorias, tais como o contraponto. Em seu sentido mais amplo, o estilo pode se referir à música como um estilo de arte, enquanto em seu sentido mais restrito, pode aplicar-se a uma única nota, a qual pode ter características estilísticas determinadas pela entoação, dinâmica, timbre e assim por diante (BEARD; GLOAG, 2005, p.128). 
Considerações teórico-metodológicas sobre o processo analítico na dissertação Suite da Epopéia Brasileira: análise da obra composicional de Delsuamy Vivekananda Medeiros (1938-2004)

Em síntese, as definições, discussões e exemplificações apresentadas por Meyer (1989), Pascall (2001) e Beard e Gloag (2005), apesar de apresentarem algumas diferenças de enfoque, complementam-se na essência do conceito de estilo, uma vez que denotam considerações relativas à contextualidade (aspectos histórico-culturais condicionantes), bem como a forma de articulação de aspectos musicais que podem ser tomados como elementos identitários de determinado estilo, seja mais geral ou individual.

\section{Considerações sobre o termo padrão}

No que diz respeito à noção de padrãos:

- 0 que serve de referência. = modelo, paradigma;

Um determinado contexto estético-musical disponibiliza uma série de padrões que são recorrentes. Por exemplo: a reprodução de modelos de estruturação dos parâmetros harmônico, melódico, bem como outros, dentro do sistema tonal (período, sentença, tipos de cadências, etc) que são compartilhados através das elaborações de cada compositor em milhares de obras. Os vários exemplos apresentados por Meyer (1989) correspondem à reprodução de padrões manifestados nos modelos da música tonal, principalmente dos séculos XVIII e XIX.

Por outro lado, na medida em que foram analisadas composições de um autor brasileiro para violão inserido no contexto de meados do século XX, os padrões que Meyer (1989) levanta não puderam ser utilizados de maneira estanque. Um enfoque desse tipo certamente levaria a uma espécie de anacronismo no processo de análise, podendo acarretar em uma indesejável justificação dos métodos analíticos empregados em detrimento do próprio objeto de estudo e do papel do analista. As análises realizadas na dissertação mostraram, por exemplo, um constante relacionamento entre perspectivas tonais e modais (tal como ocorre muitas vezes na música popular). Este aspecto demonstra a necessidade de uma abordagem que dê conta deste tipo de dinâmica estética. Entretanto, tal flexibilidade, de maneira nenhuma refutou uma idéia exposta por LaRue (1992). Para o autor, somente através da compreensão funcional dos elementos inseridos na música, podemos

[...] fazer significativas interpretações, identificando os aspectos significantes de cada peça em relação ao seu compositor e o relacionamento estilístico de cada compositor de seu ambiente ${ }^{6}$. A partir destas determinações significantes podemos nos arriscar a avaliar a música e a realização do compositor (LARUE, 1992, p.2).

5 Dicionário Priberam da Língua Portuguesa. Disponível em: 〈http://www.priberam.pt/〉.

60 autor utiliza o termo milieu para se referir ao ambiente, em termos de uma conotação social, meio social, etc. 
Considerações teórico-metodológicas sobre o processo analítico na dissertação Suite da Epopéia Brasileira: análise da obra composicional de Delsuamy Vivekananda Medeiros (1938-2004)

Composição e contexto

A consideração dos aspectos ligados ao contexto em que um determinado compositor está inserido é elemento chave na abordagem proposta por Meyer (1989). Trata-se de um olhar que se dirige, na medida do possível, à visualização de todo um universo estético-musical e sócio-histórico:

[...] na medida em que o que quer que seja replicado em uma obra de arte de um artista, um movimento, uma época, ou mesmo uma cultura, deve ser considerado como sendo escolhido pelo artista através de um conjunto de restrições [...] e por essa razão, constitui um aspecto do estilo daquele artista, assim como do estilo de um movimento, época, ou cultura (MEYER, 1989, p.7).

Dessa forma, o trabalho de análise estilística somente alcança considerações consistentemente relevantes através da organização de um referencial que traga informações acerca dos procedimentos convencionais em peças similares (LARUE, 1992, p.4). Ou seja, o conteúdo na obra de outros autores se torna um referencial importante ao processo analítico. Dessa forma, reforçou-se a tarefa de cunho comparativo entre as composições de Vivekananda com as de outros compositores/violonistas, bem a construção de um conhecimento musical mais contextualizado.

Processo comparativo/dialógico: estabelecimento de critérios

Um aspecto importante abordado por Meyer (1989), o qual reforça alguns dos critérios que foram adotados para a composição do conjunto de obras na tarefa comparativa, se deu na maneira como compositores, performers, críticos e ouvintes adquirem e desenvolvem seus conhecimentos musicais. Este conhecimento é construído quase que exclusivamente através de um método tácito:

As restrições de um estilo são aprendidas por compositores e performers, críticos e ouvintes. Geralmente, tal aprendizagem se dá em grande parte como resultado da experiência na execução e audição, ao invés de uma instrução formal na teoria musical, história ou composição. Em outras palavras, o conhecimento de estilo é geralmente 'tácito': que é, em matéria de hábitos devidamente adquiridos (internalizados) e apropriadamente trazidos à tona (MEYER, 1989, p.10).

Dessa forma, foram levantados repertórios contidos nos programas de concertos de Vivekananda, bem como em seu acervo particular de partituras. Através dessa estratégia, procurou-se ter contato mais próximo com um universo repertorial com o qual 0 violonista-compositor certamente teve contato. Tais fontes se tornam significativas na medida em que estão ligadas às suas experiências musicais práticas (execução, audição). Acredita-se que este levantamento resultou em uma interessante amostragem 
Considerações teórico-metodológicas sobre o processo analítico na dissertação Suite da Epopéia Brasileira: análise da obra composicional de Delsuamy Vivekananda Medeiros (1938-2004)

dos conteúdos que Vivekananda possivelmente teve contato. Sendo assim, buscou-se um direcionamento no sentido de "explicar o que o compositor, performer e ouvinte [Delsuamy Vivekananda conheceu][...] através deste método tácito" (MEYER, 1989, p.10), assim como estabelecer um critério para a delimitação do conjunto de obras para as análises comparativas.

Recursos violonísticos

Em decorrência do caráter do objeto de estudo, foi de grande importância considerar a inter-relação entre aspectos puramente musicais e técnico-violonísticos. Conforme Meyer (1989), o relacionamento entre as regras sintáticas disponíveis em um determinado período juntamente com o amplo campo das estratégias que podem ser tomadas pelos compositores é bastante complexo. Isto se dá na medida em que o estilo não envolve somente relacionamentos puramente musicais. Estes "[...] têm sido significantemente afetados por outros parâmetros da cultura, mais diretamente e notavelmente pela ideologia, história social, e condições de performance" (MEYER, 1989, p.20). Neste caso, os aspectos idiomáticos referentes à linguagem do violão foram considerados para a compreensão do estilo composicional de Vivekananda, principalmente em se tratando de um compositor-violonista.

Além de suas próprias obras, bem como de outros violonistas/compositores, foram utilizados como referenciais compêndios elaborados por autores como Dionisio Aguado (1784-1849), Pascual Roch (1860-1921) e Isaías Sávio (1900-1977), os quais ofereceram a possibilidade de uma leitura funcional destes recursos, trazendo significativas considerações do ponto de vista de sua identidade composicional.

Definição do estilo

Ao longo da investigação, surgiu a seguinte pergunta: como definir o estilo composicional de da obra de Vivekananda ao final deste trabalho? Um estilo "pode, em parte, ser caracterizado e definido pelo que poderia ser chamado de dominância de parâmetros" (MEYER, 1989, p.21). Para citar um exemplo observado pelo autor:

Em qualquer época dada, algumas estratégias são especialmente prevalentes. Na música da Renascença, por exemplo, certos padrões da linha do baixo ocorrem frequentemente, e alguns ritmos são particularmente característicos; no estilo Clássico, alguns padrões melódicos, progressões cadenciais e estruturas de frases estão onipresentes (MEYER, 1989, p.21).

Portanto, foi através da "dominância de parâmetros" que se buscou compreender e explicar seu estilo composicional. 


\section{Análise Schenkeriana}

A abordagem analítica schenkeriana foi utilizada para tratar das "relações entre as diversas estruturas" (FRAGA, 2009, p.7) contidas nas peças. Através da visualização dos processos lineares, pôde-se compreender como são articuladas as estruturas de fundo. Entretanto, sabe-se que não se pode atingir o que o compositor realmente pensou ou como procedeu para elaborar sua composição como um todo (em todos os níveis de escuta).

Qual o papel da análise neste trabalho?

Se não podemos remontar o pensamento do compositor como um todo através de uma determinada composição, qual o papel da análise musical? É importante problematizar e posicionar este tipo de enfoque musicológico através da relação entre o raciocínio composicional e o raciocínio analítico:

[...] 0 compositor constrói; o analista 'des-constrói'. 0 fato do compositor não considerar certas relações não significa que estas não estejam lá e que não possam ser observadas pelo analista. Idéias assim materializadas podem ganhar um novo status. Ao teórico é dado o direito à especulação filosófica, tanto quanto é dado ao compositor o direito à liberdade de expressão artística (FRAGA, 2009, p.X).

Dessa forma, tomou-se como premissa básica não buscar "entrar na mente" do compositor, uma vez que isso seria impossível. 0 que se buscou, foram as variadas "materializações" que surgiram a partir da relação do analista com a obra. Ou seja, o conhecimento, no caso desta pesquisa, se deu através da relação estética (produto final alcançado no diálogo dos processos de escuta e crítica) que o próprio analista teve enquanto experiência junto à obra analisada que, além de outras estratégias, norteou a interpretação.

Análise schenkeriana pós século XIX

A ferramenta analítica schenkeriana foi utilizada através da perspectiva de Salzer (1952). Para este autor é um grande equívoco tomar a abordagem desenvolvida por Heinrich Schenker (1868-1935) considerando seus postulados estético-ideológicos de forma essencialista. Esse tipo de pensamento ocorre quando se toma sua abordagem a partir de uma perspectiva estanque e unilateral, não considerando outras manifestações do 
Considerações teórico-metodológicas sobre o processo analítico na dissertação Suite da Epopéia Brasileira: análise da obra composicional de Delsuamy Vivekananda Medeiros (1938-2004)

fenômeno tonal. As idéias de Schenker "podem aplicar-se e estender-se aos estilos de música mais diversos e que a ampla concepção que fundamenta sua proposta não está confinada a nenhum período histórico da música" (SALZER, 1952, p.18).

Pankhurst (2008) divide o mesmo ponto de vista. Para o autor, uma das maneiras em que a abordagem schenkeriana pode ser utilizada em repertórios pós século XIX, está em contrapor estruturas tonais tradicionais àquelas das peças que estão sendo analisadas, ou seja, àquelas que forçam "as fronteiras do repertório tonal" (PANKHURST, 2008, p.182). 0 autor ainda sugere que "[...] a questão não vem a ser 'como pode esta peça ser compreendida como uma elaboração da Ursatz?', mas, 'de que modo essa peça diverge das práticas da harmonia tradicional e de condução de vozes conforme descritas pela teoria schenkeriana?'"' (PANKHURST, 2008, p.182)?

Portanto, as análises estruturais realizadas através da ferramenta schenkeriana, fundamentadas nas perspectivas apresentadas por Salzer (1952), Pankhurst (2008) e Lívero de Souza (2009) foram dirigidas dentro da compreensão de que o tonalismo defendido por Schenker não se circunscreve somente às suas perspectivas ideológico-musicais, evitando-se assim, anacronismos.

Audição e análise

A análise schenkeriana foi realizada de forma dialogada com um aspecto que a nosso ver possui extrema importância no processo analítico: a consideração da própria percepção auditiva. Conforme Bent e Drabkin (1998), "subjacente a todos os aspectos da análise como uma atividade fundamental é o ponto de contato entre a mente e o som musical, ou seja, a percepção" (BENT; DRABKIN, 1998, p.1). Pankhurst (2008) também destaca a percepção musical como atividade elementar e essencial à análise. De uma maneira ou de outra, a análise está integrada na vida musical do indivíduo que realiza uma escuta reflexiva, principalmente por sermos suscetíveis à identificação de padrões e suas repetições. Sendo assim, seja como performers ou ouvintes, acabamos entrando no "reino da análise" (PANKHURST, 2008, p.3). Forte e Gilbert (1992), por sua vez, comentam que, mesmo para a obtenção de considerações analíticas convincentes dentro da abordagem schenkeriana, é necessário o "desenvolvimento de um bom ouvido e inteligência musical" (FORTE; GILBERT, 1992, p.62). Sendo assim, destacam que a intuição e um desenvolvido intelecto musical, aliados aos conceitos schenkerianos, oferecem uma "penetração muito mais profunda aos aspectos da música" (FORTE; GILBERT, 1992, p.62). Salzer (1952) destaca que sua abordagem considera, bem como está alicerçada sobre 0 que o próprio autor chama de audição estrutural:

A compreensão dos organismos tonais é um problema de audição; o ouvido tem que ser sistematicamente adestrado, não somente para escutar a sucessão de notas, linhas melódicas e progressões de acordes, mas também para assumir seu significado estrutural e sua coerência. [...] A essa abordagem chamo audição estrutural (SALZER, 1952, p.18).

$7 \quad$ Nota-se que este autor deixa clara a importância de uma leitura dialógica neste caso, o que de certa forma aproxima-se da premissa básica da análise estilística. 

da Epopéia Brasileira: análise da obra composicional de Delsuamy Vivekananda Medeiros (1938-2004)

0 autor também observa que os próprios gráficos "simbolizam os processos da audição estrutural" (SALZER, 1952, p.157), chamando atenção para a relação existente entre escuta e sua "verbalização". Finaliza: "[...] creio firmemente que a audição estrutural reforça o ouvido e a idéia criativa e interpretativa [...], e que uma compreensão da audição estrutural [...] leva a aprofundar-nos nos problemas da composição e da estrutura musical [...]" (SALZER, 1952, p.158).

Apoiado nas considerações acerca da audição no processo analítico que os autores levantados acima teceram, a realização deste trabalho esteve constantemente ligada ao diálogo entre premissas teóricas e percepção auditiva, a fim de que os gráficos analíticos não refletissem puramente a confirmação de aspectos pertinentes ao campo teórico, mas sim, que refletissem explicações de ordem crítica em que a escuta encontra-se apoiando e sendo apoiada por conceitos teóricos.

Movimento dirigido

As análises foram tomadas através da consideração da música enquanto movimento dirigido:

A música tonal da civilização ocidental se baseia no movimento, mas não no movimento pelo simples movimento. Representa movimento tudo o que tem um objetivo, o que desde seu começo mostra uma direção até um certo fim. No caminho até este fim, encontramos detalhes e desvios; escutamos acordes, notas e passagens que dão forma a esses detalhes, e que servem para tornar o caminho até o objetivo mais interessante e cheio de cor. Mas tais acordes e notas, tem somente uma influência indireta sobre o movimento principal até esse objetivo, que permanece intacto em seu significado absoluto (SALZER, 1952, p. 58).

Este aspecto corrobora com a perspectiva de LaRue (1992), quando observa que uma determinada proposta analítica deve estar relacionada à noção de que a música é uma espécie de manifestação de movimento sonoro, onde todos os elementos constituintes se inter-relacionam para confirmar, reduzir ou intensificar essa sensação (LARUE, 1992, p.1). A título de exemplificação, vejamos os tipos básicos de movimento que Forte e Cilbert (1992) e Salzer (1952) abordam. Os primeiros comentam que a prolongação melódica ${ }^{8}$ está fundada no conceito de diminuição, à qual está diretamente relacionada à produção de movimento (FORTE; GILBERT, 1992, p.202) ${ }^{9}$. Mais tarde, destacam os três tipos principais de prolongação melódica:

8 "0 conceito de prolongação é fundamental na análise schenkeriana; se refere aos modos em que um componente musical - uma nota (prolongação melódica) ou um acorde (prolongação harmônica) - permanece vigente sem estar literalmente representado a cada momento" (FORTE; GILBERT, 1992, p.201).

9 Salzer (1952, pp.68-71), no tópico Las funciones de la armonía y el contrapunto, destaca que: os fatores ligados ao movimento (a prolongação e os processos de diminuição) são advindos dos elementos do contraponto; os fatores geradores de estabilidade e estrutura vêm de concepções harmônicas. Mais tarde, o próprio autor observa que a concepção contrapontística "transcendendo seu papel geralmente aceito [...] representa a força fundamental do movimento musical (SALZER, 1952, p.70). 

da Epopéia Brasileira: análise da obra composicional de Delsuamy Vivekananda Medei$\operatorname{ros}(1938-2004)$

$\begin{aligned} & \text { 1. Movimento desde uma nota dada: } \\ & \text { normalmente um segmento de escala } \\ & \text { ou arpejamento diatônico descendente } \\ & \text { (aonde a prolongação segue a nota que } \\ & \text { se prolonga); }\end{aligned}$
$\begin{aligned} & \text { 2. Movimento até uma nota dada: nor- } \\ & \text { malmente um segmento de escala ou } \\ & \text { arpejamento diatônico ascendente (aon- } \\ & \text { de a prolongação precede a nota que se } \\ & \text { prolonga); }\end{aligned}$
$\begin{aligned} & \text { 3. Movimento ao redor de uma nota } \\ & \text { dada: muito frequentemente por meio } \\ & \text { de uma bordadura superior, uma borda- } \\ & \text { dura inferior ou ambas (que podem ser } \\ & \text { prolongadas). }\end{aligned}$

Tabela 1: Três tipos básicos de movimento (FORTE; GILBERT, 1992, p.202).

Por sua vez, Salzer (1952) também discorre e exemplifica os três tipos básicos de movimento:

Atendendo à direção ou estrutura básica das melodias tonais, e às prolongações desta estrutura, temos encontrado, e seguiremos encontrando cada vez com mais freqüência, que tanto a estrutura como as prolongações melódicas podem se expressar de três formas: ou aparece em forma de uma linha contínua que conecta duas notas diferentes, podendo chamar esse tipo de movimento de intervalo-llenado ${ }^{10}$, ou na forma de um movimento ao redor de uma nota, representando então o tipo de movimento ornamental. Além disso, o compositor pode usar o tipo de movimento chamado intervalo-perfilado"11, [...] (SALZER, 1952, p.135).

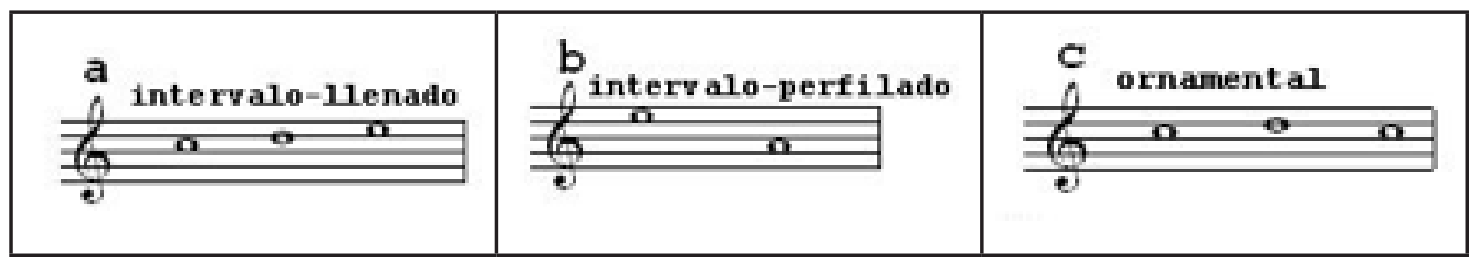

Tabela 2: Exemplos transcritos em Salzer (1952, p.363).

Da mesma forma que Forte e Gilbert (1992), Salzer (1952) também destaca a combinação entre os tipos de movimentos a partir da idéia de movimento ornamental ao redor de uma determinada nota:

10 Llenado: no sentido de preenchido, recheado, etc.

11 Perfilado: no sentido de perfil, de que traça um perfil. 

da Epopéia Brasileira: análise da obra composicional de Delsuamy Vivekananda Medeiros (1938-2004)
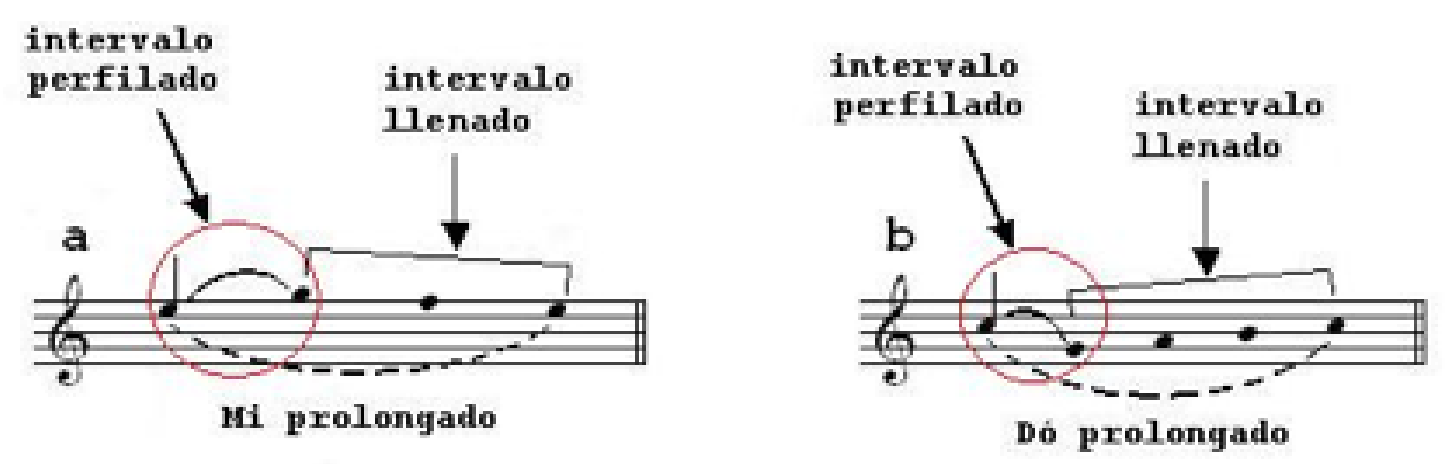

Figura 1: Movimentos ao redor de uma nota (SALZER, 1952, p.363).

Dessa forma, a organicidade na música se dá no sentido de que a função e significado das notas e acordes, assim como seus inter-relacionamentos, dependem do objetivo direcional ao qual estão destinadas (SALZER, 1952, p.33) ${ }^{12}$.

As análises foram realizadas através do conceito de movimento dirigido, uma vez que o próprio analista compartilha tal premissa com os autores. Isso proporcionou uma relação entre os pressupostos teóricos, auditivos e motores, uma vez que a experienciação ao instrumento foi uma prática constante no processo analítico, trazendo outras possibilidades de percepção e reflexão acerca da obra analisada.

Organização das análises

A fim de organizar o processo analítico como um todo, bem como apresentar uma estruturação em termos de capítulos de forma mais inteligivel ao leitor, foram tomados como modelos algumas das proposições de Fraga (2009) e de Lívero de Souza (2009). 0 primeiro, trata diretamente de uma metodologia para dirigir um processo analítico; a segunda, apresenta, através de sua tese, uma organização bastante clara das perspectivas analíticas adotadas:

1. Preparação da superfície: observação de aspectos gerais como forma, harmonia, construção de frase, motivos, temas, etc. [...] Cuidados devem ser tomados ao se eliminar as vozes internas quando é o caso, pois estas, às vezes, são importantes para o entendimento do todo.

2. Nível Frontal: procurar estabelecer os principais movimentos harmônicos, determinando as metas locais e as metas gerais. Neste ponto já podemos tentar encontrar em caráter provisório, uma linha fundamental de 3 š ou 5 š (com ou sem interrupção) que abranja a obra toda.

3. Análise das camadas - elaboração do(s) gráfico(s): não existe uma regra de siste-

12 Para melhores esclarecimentos, ver Capítulo 2.B. Música como movimento dirigido. Estrutura e prolongação (SALZER, 1952, p.33-36). 
Considerações teórico-metodológicas sobre o processo analítico na dissertação Suite da Epopéia Brasileira: análise da obra composicional de Delsuamy Vivekananda Medeiros (1938-2004)

matização para iniciar a confecção de um gráfico. Pode-se começar pela melodia ou pelo baixo. Pode-se optar por estabelecer uma LF geral, concentrando-se depois nos detalhes. Ou, pelo contrário, pode-se trabalhar conjuntamente os detalhes de melodia e de baixo paulatinamente à medida que o trabalho avança. Para se chegar a um resultado satisfatório nesta fase podem ser necessários vários gráficos [...].

4. Plano de fundo: explica o funcionamento da grande estrutura quanto ao seu movimento linear. É interessante que cada gráfico seja acompanhado de observações que exponham por escrito os principais pontos da análise [...] (FRAGA, 2009, p.69).

Através do trabalho de Lívero de Souza (2009) tomou-se como base de organização as etapas de análises realizadas da peça Sonata de Louvação de Eunice Katunda, o que de certa maneira apresenta uma grande similaridade à proposição do primeiro. A autora dividiu da seguinte maneira:

- Análise de superfície: Materiais (modos, motivos, dimensões horizontal e vertical, textura, ritmo, estrutura - partes);

- Vozes condutoras (gráficos analíticos schenkerianos).

Dessa forma, pretendeu-se estabelecer um trabalho com o intuito de facilitar a leitura e compreensão.

\section{Referenciais De Análise Para Superfície}

Para fundamentar as análises de superfície, correspondentes à forma musical, harmonia, etc, foram tomados como referenciais autores como Green (1979), Schoenberg (1991; 2001; 2004), Piston (1998), dentre outros. 0 primeiro foi utilizado como referencial no que diz respeito à estruturação formal, principalmente, do ponto de vista harmônico. Um dos aspectos que o justificam dentro deste conjunto de referenciais é o fato de que o próprio autor expõe no prefácio de seu livro que muitos conceitos foram tomados de Structural hearing de Felix Salzer: "Embora aplicada de uma maneira diferente e, de fato, para diferentes fins, a visão de forma como uma interação de estrutura tonal e design deve sua origem ao livro do Dr. Salzer" (GREEN, 1979, p.7).

0 livro Schoenberg (1991), deu suporte a:

- Considerações sobre os materiais utilizados (motivos, estruturas frasais, etc);

- Problematizações a respeito de modelos de estruturação nos mais variados níveis;

- Dentre outros aspectos. 
Considerações teórico-metodológicas sobre o processo analítico na dissertação Suite da Epopéia Brasileira: análise da obra composicional de Delsuamy Vivekananda Medeiros (1938-2004)

Conforme Gerald Strang, o livro de Schoenberg apresenta "pouca referência à música posterior a 1900", entretanto, os métodos construtivos abordados por Schoenberg, embora amplamente tradicionais, são aplicáveis a "uma grande variedade de estilos musicais [...]", podendo ser utilizado também, conforme o autor do prefácio, "como um texto de análise" (STRANG in SCHOENBERG, 1991, p.18).

Schoenberg (2001; 2004), Piston (1998), Persichetti (1985), assim como outros, foram utilizados em relação a aspectos que envolveram diretamente a harmonia. Vale destacar este último, o qual contribuiu, principalmente, na análise da Suíte da Epopéia Brasileira (19[78]), por apresentar elaborações harmônicas e melódicas advindas de uma concepção modal, assunto do qual o Persichetti (1985, p.29-41) trata no capítulo Materiales de la escala.

\section{Considerações gerais sobre a abordagem metodológica}

Conforme dito anteriormente, o próprio referencial principal, ou seja, os conceitos e práticas da análise estilística discutidas por Meyer (1989), possuem um importante papel no que diz respeito à organização metodológica deste trabalho. Em linhas gerais, trata-se de uma abordagem que proporciona a construção de uma investigação da(s) obra(s) de um determinado compositor dentro de seu(s) contexto(s), ou seja, uma visão panorâmica de um determinado universo.

Considerações metodológicas gerais referentes à análise estilística

0 estabelecimento do conjunto de obras a serem analisadas é uma das principais premissas metodológicas observadas por Meyer (1989). Sendo assim, partiu-se da seguinte colocação: "As obras em um grupo, ou repertório, as quais são tratadas como um conjunto, terão sempre características comuns, mas as bases para a seleção podem ser completamente variadas" (MEYER, 1989, p.38). Abaixo, alguns exemplos de critérios exemplificados pelo autor:

- As obras de um único compositor (divididas em períodos ou tomadas como um todo);

- Obras de um grupo de compositores, geralmente, mas não necessariamente, escritas durante um determinado período de tempo e na mesma cultura (por exemplo, o repertório da chanson parisiense, do classicismo vienense, do impressionismo - se francês, inglês ou americano);

- Obras escritas na mesma área geográfica ou tradição nacional [...];

- Obras escritas em um gênero particular (ópera, lied, música de câmara, [...]);

- Obras escritas por algum segmento socialmente definido de uma cultura, talvez transcendendo os limites culturais ou geográficos (música folk, música popular); 
Considerações teórico-metodológicas sobre o processo analítico na dissertação Suite da Epopéia Brasileira: análise da obra composicional de Delsuamy Vivekananda Medeiros (1938-2004)

- Obras escritas por algum propósito utilitário (música litúrgica, música militar, música para fábricas);

- Obras escritas sobre um considerável período de tempo em uma mesma área cultural ampla (no oeste, música da renascença, barroca);

- A música de toda uma civilização ou de um segmento desta (música de culturas do Pacífico sul, música indígena americana, música ocidental desde a Renascença) (MEYER, 1989, p.38).

Além disso, "as possíveis divisões e subdivisões são inumeráveis. Como em qualquer disciplina, os meios os quais as entidades são agrupadas, dependem dos interesses do investigador" (MEYER, 1989, p.39). Sendo assim, a constituição do conjunto de obras a serem dialogadas no processo analítico comparativo à obra de Vivekananda pautou pelas seguintes estratégias:

- Consulta ao acervo particular de partituras do violonista;

- Consulta e análise dos repertórios contidos nos programas de concertos levantados;

- Consideração do contexto estético-cultural referente ao violão de concerto no Brasil a partir de outras fontes (livros, teses, dissertações, revistas, etc);

- A consideração ao fato de que Vivekananda, assim como outros, se caracterizava como um violonista-compositor, característica essa que, conforme Perotto (2007, p.2-3), é bastante comum na cultura do violão de concerto;

- Dentre outros aspectos.

A partir destes critérios adotados foi possível delimitar um campo repertorial para a realização das análises, o qual proporcionou a visualização de um contexto cujos conteúdos estéticos certamente o intérprete teve contato, seja em seu processo de estudo particular, seleção de obras para seus alunos, montagem de repertórios para concertos, contexto mais geral referente ao violão de concerto no Brasil, etc. Portanto, acredita-se que através destes procedimentos metodológicos, pôde-se alcançar uma estratégia inteligível para a realização do trabalho de análise estilística proposto.

\section{Considerações finais}

As questões (destacadas no início deste artigo) que motivaram a realização da pesquisa em torno da análise estilística da obra composicional de Delsuamy Vivekananda levaram, consequentemente, à perspectiva comparativa. Além disso, a constituição de um contexto relacionado à "produção composicional violonística brasileira no século XX" trouxe a perspectiva de uma abordagem mais cultural, na medida em que foi definido um território o qual pudesse fornecer elementos capazes de dar subsídios suficientes 
Considerações teórico-metodológicas sobre o processo analítico na dissertação Suite da Epopéia Brasileira: análise da obra composicional de Delsuamy Vivekananda Medeiros (1938-2004)

para a compreensão do estilo composicional deste violonista-compositor no âmbito da produção nacional para o instrumento.

A composição do campo teórico-conceitual (MEYER, 1989; LARUE, 1992; SALZER, 1952; FORTE, GILBERT, 1992; etc) que fundamentou a dissertação foi crucial para nortear todo o processo analítico. A relação entre os conceitos trabalhados a partir destes autores com as reflexões advindas do processo de escuta, percepção, bem como das experiências musicais do analista proporcionaram um processo interpretativo e crítico que, no mínimo, pode-se dizer adequado para os padrões de um trabalho acadêmico. Dessa forma, pode-se dizer: o campo teórico-conceitual forneceu uma base para que as considerações analíticas pudessem vir a tona através da interpretação do analista.

A partir de tudo o que foi exposto, acredita-se que o presente artigo atinge seu principal objetivo: o de trazer uma pequena contribuição para as discussões relacionadas à subárea Análise Musical no âmbito da Musicologia brasileira, discorrendo sobre a articulação entre referenciais teóricos, metodologias e objetos de pesquisa. 
Considerações teórico-metodológicas sobre o processo analítico na dissertação Suite da Epopéia Brasileira: análise da obra composicional de Delsuamy Vivekananda Medeiros (1938-2004)

\section{Referências}

> AGUADO, Dionisio. Escuela de guitarra por Don Dionisio Aguado. Madrid: 1825, 1825. > ANTÔNIO, Paulo. Sávio homenageado em Porto Alegre. Violão e Mestres. São Paulo, n.9, p.27-28, 1968.

$>$ BEARD, David; GLOAG, Kenneth. Musicology, The Key Concepts. London: Routledge, 2005.

> BENT, Ian; DRABKIN, William. Analisys. In: The New Grove Handbooks in music. London: Macmillan, 1998.

> CALDAS, Pedro Henrique. História do Conservatório de Música de Pelotas. Pelotas: Semeador, 1992.

> FORTE, Allen; GILBERT, Steven. Introducción al analisis schenkeriano. Trad.Pedro Purroy Chicot. Barcelona: Labor, 1992.

$>$ GREEN, Douglass. Form in tonal music: na introduction to analysis. USA: Holt, Rinehart and Winston, 1979.

> LARUE, Jan. Guidelines for style analysis. Warren: Harmonie Park Press, 1992.

> MEDEIROS, Daniel Ribeiro. Suíte da Epopéia Brasileira: análise da obra composicional de Delsuamy Vivekananda Medeiros (1938-2004). 149f. Dissertação (Mestrado em Musicologia) - Universidade Federal do Paraná, Curitiba, 2010.

$>$ MEYER, Leonard. Style and music: theory, history, and ideology. Chicago: University of Chicago, 1989.

> PASCALL, Robert. Style. In: New Grove Dictionary of Music and Musicians. V.24. New York: Oxford Press, Inc. 2001, pp.638-642.

> PEROTTO, Leonardo Luigi. A obra para violão de Pedro Cameron: características idiomáticas e estilísticas. 2007. 479f. Dissertação (Mestrado em Música) - Escola de Música e Artes Cênicas, UFG, Goiânia.

$>$ PERSICHETTI, Vincent. Armonia del siglo XX. Trad. Alicia Santos Santos. Madrid: Real Musical Publicaciones y Ediciones, 1985.

> PISTON, Walter. Armonía. Revisada e ampliada por Mark DeVotto. Espanha: Span Press Universitaria, 1998.

$>$ PANKHURST, Tom. SchenkerGUIDE: a brief handbook and web site for Schenkerian analysis. New York: Routledge, 2008.

$>$ ROCH, Pascual. A modern method for the guitar (School of Tárrega) - Volume II. New York: Schirmer, 1917.

> SALZER, Felix. Audición estructural: coherencia tonal en la música. Trad. Pedro Purroy 
Considerações teórico-metodológicas sobre o processo analítico na dissertação Suite da Epopéia Brasileira: análise da obra composicional de Delsuamy Vivekananda Medeiros (1938-2004)

Chicot. Barcelona: Labor, 1952.

> SÁVIO, Isaías. Efeitos violonísticos e modo de execução dos ornamentos musicais. São Paulo: Ricordi, 1973.

> SCHOEnBERG, Arnold. Fundamentos da Composição Musical. Trad. Eduardo Seincman. São Paulo: Editora da Universidade de São Paulo, 1991.

> SOUZA, Iracele A. Lívero de. Louvação à Eunice: Um estudo de análise da obra para piano de Eunice Katunda. 2009. 57of. Tese (Doutorado em Música)-Instituto de Artes, Universidade Estadual de Campinas (UNICAMP), Campinas.

> SOUZA, Márcio de. 1968: o violão chega à faculdade. Assovio. Porto Alegre, n. 7, p. 5 , mar. 2001.

> SOUZA, Márcio; PORTO, Patrícia Pereira. Violonistas. In: NOGUEIRA, ISABEL PORTO (Org.). História Iconográfica do Conservatório de Música da UFPel. Porto Alegre: Pallotti, 2005.

Daniel Ribeiro Medeiros, Bacharel em Música - Habilitação em Violão pela Universidade Federal de Pelotas (2004) e Mestre em Música (Interpretação/Processos Criativos: Teoria, Criação Musical e Estética) pela Universidade federal do Paraná (2010), sob orientação do Prof. Dr. Norton Dudeque. Em suas pesquisas, tem abordado temáticas relacionadas a Teoria e Análise Musical e historiografia musical juntamente a aspectos culturais. São trabalhos que envolvem investigações no âmbito da chamada música "culta" e música popular, tal como rock, por exemplo. Atualmente, atua como professor temporário no curso de Música - Modalidade Licenciatura da Universidade Federal de Pelotas (UFPel). Atualmente realiza doutorado no Programa de Pós-Graduação em Memória Social e Patrimônio Cultural. danielribeiromedeiros@gmail.com 